\title{
On the Cover of This Issue: Hugoniot Data and Equation of State Parameters for an Ultra-High Performance Concrete
}

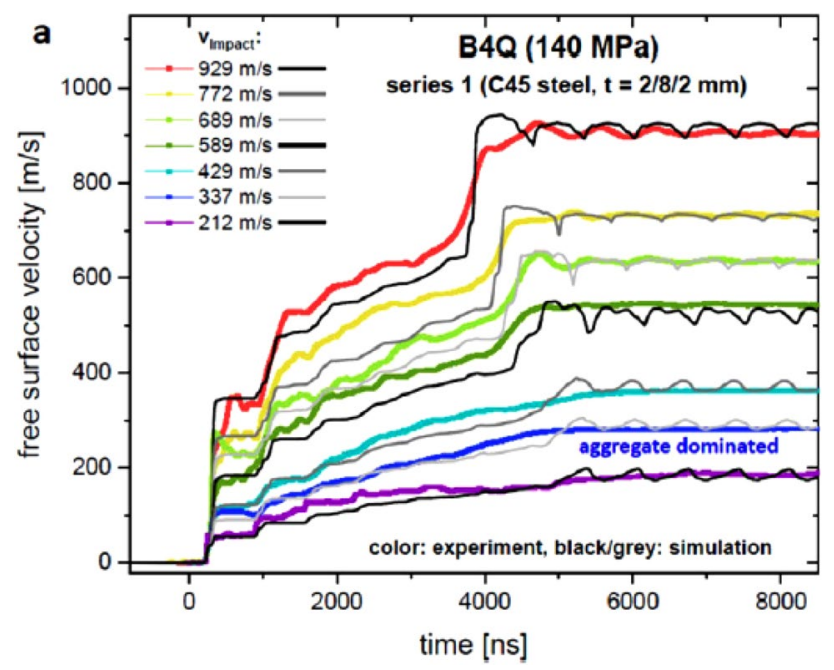

Publisher's Note Springer Nature remains neutral with regard to jurisdictional claims in published maps and institutional affiliations. 